\title{
Effects of microstructure on the dynamic strain aging of ferritic- pearlitic steels at high strain rates
}

\author{
Ahmad Mardoukhi ${ }^{1}$, Jari Rämö ${ }^{1}$, Taina Vuoristo $^{2},{\text { Amandine } \text { Roth }^{3} \text {, Mikko Hokka }}^{1}$, Veli-Tapani Kuokkala ${ }^{1}$ \\ ${ }^{1}$ Tampere University of Technology, Laboratory of Materials Science, POB 589, 33101 Tampere, Finland \\ ${ }^{2}$ Swerea KIMAB AB, Box 7047, 16407 Kista, Sweden \\ ${ }^{3}$ Schmolz + Bickenbach Group CREAS, BP 70045, 57301 Hagondance Cedex, France
}

\begin{abstract}
This paper presents an experimental study of the effects of dynamic strain aging on the mechanical behavior of selected high carbon and chromium-manganese steels in dynamic loading condition. In ferritic-pearlitic steels, the dynamic strain aging is typically caused by carbon, nitrogen, and possibly some other small solute atoms. Therefore, the thermomechanical treatments affect strongly how strong the dynamic strain aging effect is and at what temperature and strain rate regions the maximum effect is observed. In this work, we present results of the high temperature dynamic compression tests carried out for two different ferritic-pearlitic steels, $16 \mathrm{MnCr} 5$ and $\mathrm{C} 60$, that were heat treated to produce different microstructure variants of these standard alloys. The microstructures were analyzed using electron microscopy, and the materials were tested with the Split Hopkinson Pressure Bar device at three different strain rates at temperatures ranging from room temperature up to $680{ }^{\circ} \mathrm{C}$ to study the effect of the heat treatments and the resulting microstructures on the dynamic behavior of the steels and the dynamic strain aging effect. The results indicate that for both steels, a coarse grain structure has the strongest dynamic strain aging sensitivity at small plastic strains. However, at higher strains, all microstructures show similar strain aging sensitivities.
\end{abstract}

\section{Introduction}

The strength of steels is very sensitive to both deformation rate and ambient temperature. At low and intermediate strain rates, thermally activated dislocations motion is controlling the plastic deformation of steels. Consequently, the plastic behavior of steels is affected by the characteristics of the particular glide obstacles that the dislocations need to pass. The nature and density of these obstacles can change during plastic deformation, which may lead to a change in the material's response during the loading process. At high strain rates, viscous drag becomes the dominant resisting mechanism against plastic deformation due to its effects on the dislocations. For most steels, the deformation mechanism changes from thermally activated dislocation motion to drag controlled dislocation motion at strain rates close $10^{3} \mathrm{~s}^{-1}$. This leads to the commonly observed strong transient hardening, i.e., increase of the momentary flow stress of the steels. The permanent strain hardening of BCC steels, on the other hand, is not much affected by the strain rate or temperature. The reason for this is that the main thermally activated mechanisms are independent of the amount of deformation. In the case of pearlitic steels, the most significant obstacle for thermally activated dislocation motion is the lattice friction. This is due the fact that the lattice structure lacks close packed slip planes. Therefore, the stress-strain curves obtained for
BCC metals at different temperatures usually have the same shape and only the overall level of flow stress decreases by increasing temperature. However, at higher temperatures, where the diffusion of small alloying atoms such as carbon and nitrogen increases, a sudden increase in the flow stress can be observed at certain strain rate-temperature combinations. In addition, at lower strain rates, jerky or serrated flow can be observed. This behavior is known as dynamic strain aging (DSA) or the Portevin-Le Chatelier phenomenon [1]. The reason for this behavior can be found in the fast movement of alloying atoms that temporarily pin the dislocations by diffusing into the dislocation cores. This leads to the minimization of lattice strain energy caused by the dislocations. Consequently, further movement of the dislocations requires additional work to release them from the cloud of alloying atoms. At higher strain rates, dynamic strain aging can cause an increase in the strength of the material at higher temperatures. This behavior has been observed for many metals and alloys, such as titanium [2], niobium [3], vanadium [4], molybdenum [5], and stainless steels [6]. However, for the work presented in this paper, the previous research on iron and carbon steels has more significance. Baird and Jamieson [7] studied the effects of nitrogen and manganese on the high temperature tensile behavior of iron at low strain rates and concluded that the alloying atoms cause both strong solid solution strengthening and

*Ahmad Mardoukhi: ahmad.mardoukhi@tut.fi 
dynamic strain aging. Gilat and $\mathrm{Wu}[8]$ studied the behavior of 1020 steel at different strain rates in shear and reported that strong dynamic strain aging occurs in the range of $200-400{ }^{\circ} \mathrm{C}$ depending on the strain rate. The effect was reported to be very strong up to a strain rate close to $5 \times 10^{-4} \mathrm{~s}^{-1}$, after which the effect started to fade away with increasing strain rate. Shahriary et al. [9] analyzed the stress-strain curves of the 4340 steel at different temperatures. They reported that both the work hardening exponent as well as the ductility of the steel were affected by the dynamic strain aging, the former increasing and the latter decreasing in the temperature range of $250-300{ }^{\circ} \mathrm{C}$. The reduced ductility in the temperature range of $250-400{ }^{\circ} \mathrm{C}$ is commonly known as blue brittleness, and it has been attributed to dynamic strain aging [10].

Dynamic strain aging is a diffusional process, whose strength is affected by strain rate (time), temperature, density of mobile dislocations, and concentration of small mobile atoms [11]. Nonetheless, the situation is not quite straightforward, as steels with the same chemical composition can have a vast difference in their microstructures and mechanical properties due to the heat treatments and different processing methods. For example, thermomechanical treatments can influence significantly the local chemical compositions, phase fractions, amount of precipitates, dislocation density, grain size etc. Therefore, the strength of the dynamic strain aging is also affected by the actual microstructure of the material. In the literature, however, there are only few examples of how the processing and microstructure of steels affect the strength of dynamic strain aging. One example is the work of Chakravartty et al. [12], who studied nickel-manganese steels with different aging temperatures and cold worked microstructures up to 250 ${ }^{\circ} \mathrm{C}$. The authors concluded that the microstructure of the steel has a very small effect on the strength of dynamic strain aging. However, Wagner et al. [13] reported the opposite for the A48 steel. According to the authors, higher amount of martensite leads to reduced dynamic strain aging.

This work presents the results of a systematic study on the dynamic strain aging effects in two different steels. Four thermomechanical heat treatments were carried out for two steels to produce samples with different ferritic-pearlitic structures. The dynamic strain aging and its effects on the material response were characterized at dynamic strain rates and at temperatures up to $680{ }^{\circ} \mathrm{C}$. The correlation between the microstructure and the strength of the dynamic strain aging offers new insight for a better understanding of the phenomena affecting the strength and hardening of steels at high temperatures.

\section{Experimental procedure}

Two different steels were studied in this work, a high-carbon steel C60 and a chromium-manganese steel $16 \mathrm{MnCr} 5$. The studied steels had different microstructures depending on the heat treatment, i.e., coarse grain $(\mathrm{CG})$, globular pearlite (GP), and banded structure (WB), which are shown in the scanning electron (SEM) micrographs in Figure 1. The C60 steel was tested in the reference, CG, and GP states, whereas the $16 \mathrm{MnCr} 5$ steel was studied in $\mathrm{CG}, \mathrm{GP}$, and WB structures. Cylindrical samples with a diameter of $8 \mathrm{~mm}$ and a length of $8 \mathrm{~mm}$ were prepared from each material. Table 1 shows the chemical compositions of the tested materials.
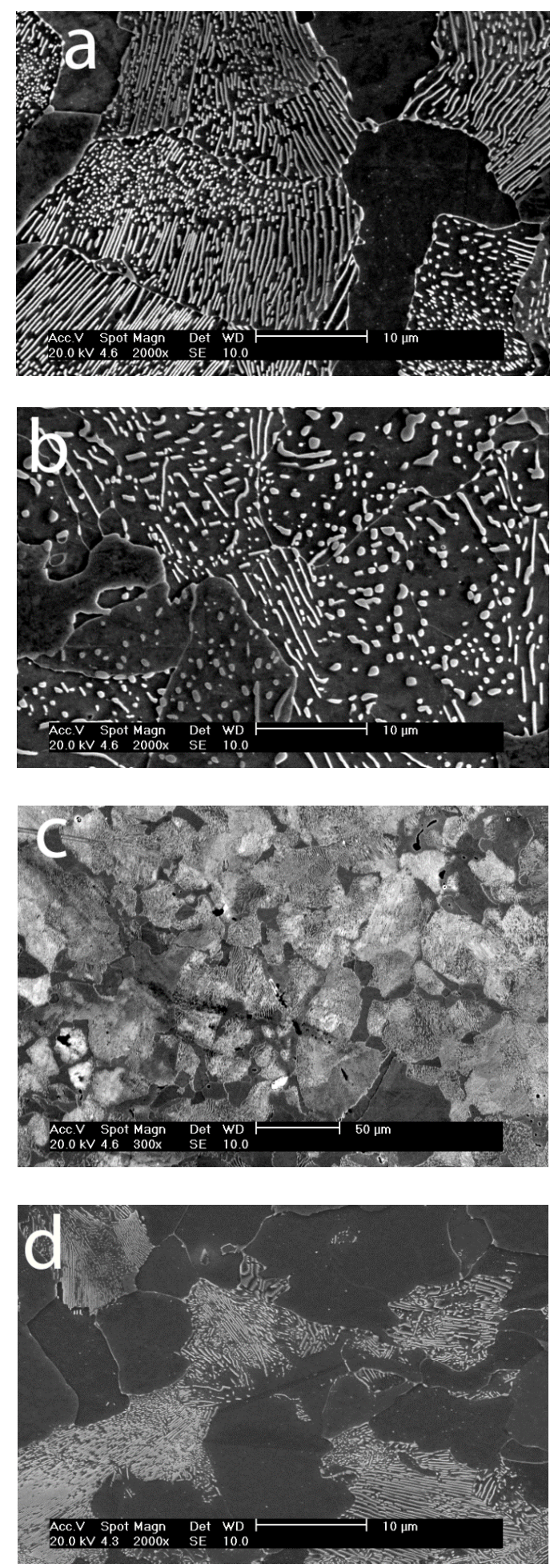

Fig. 1. Different microstructures of the a) C60 steel reference structure, b) C60 steel globular pearlite structure, c) C60 steel coarse grain structure, and d) $16 \mathrm{MnCr} 5$ banded structure. 
Table 1. Chemical composition of the tested steels.

\begin{tabular}{|c|c|c|c|c|c|c|}
\hline $\begin{array}{c}\text { Chemical } \\
\text { Composition } \\
\text { (Wt\%) }\end{array}$ & $\mathrm{C}$ & $\mathrm{Si}$ & $\mathrm{Mn}$ & $\mathrm{P}$ & $\mathrm{S}$ & $\mathrm{Cr}$ \\
\hline $\mathrm{C} 60$ & $0.57-$ & $<0.4$ & 0.60 & $<0.0$ & $<0.0$ & $<0.4$ \\
& 0.65 & 0 & - & 45 & 45 & 0 \\
\hline $16 \mathrm{MnCr} 5$ & $0.14-$ & $<0.4$ & 1.00 & $<0.0$ & $<0.0$ & $0.80-$ \\
& 0.19 & 0 & - & 25 & 35 & 1.10 \\
\hline
\end{tabular}

The high strain rate tests were carried out using a Split Hopkinson Pressure Bar (SHPB) device. The pressure bars were made of Maraging steel with a diameter of $22 \mathrm{~mm}$ and the length of $1200 \mathrm{~mm}$. The striker bars of the same material were used with the length of $200-400 \mathrm{~mm}$ to perform the tests at different strain rates. The bars were resting on adjustable stanchions and supported by bearings allowing accurate alignment of the bars in z- and y-directions. The striker bar was impacted on the free end of the incident bar using an air gun. Three optical IR sender-receiver pairs were used to measure the impact velocity of the striker, and two active strain gages were attached to the center of the incident and transmitted bars to record the strain pulses. The strain gage signals were amplified using a Kyowa CDV 700A series signal conditioner and recorded on a 12-bit 10MSample Yokogawa digital oscilloscope. All functions of the device, including loading and shooting of the striker as well as reading of the data from the oscilloscope, are computer controlled. The high temperature SHPB setup comprises a mechanical manipulator, which controls the bars, and a specimen holder arm that is used to move the sample in and out from the furnace. The furnace is placed next to the bars to avoid heating of the bars. The sample is placed in a soft ceramic wool ring, which is held by a specimen holder arm. The arm can be moved by a pneumatic actuator back and forth between the centerline of the bars and the furnace. The first step in the high temperature SHPB test is to heat the sample inside the furnace. The sample is kept in the furnace long enough to achieve a homogeneous temperature over the sample. The second and third steps are to rapidly pull out the specimen to the centerline of the bars and to shoot the striker bar. The second mechanical manipulator at the end of a momentum trap bar pushes the incident and transmitted bars and the sample into contact just a fraction of a second $(\sim 50 \mathrm{~ms})$, before the impact of the striker and the incident bar. This short contact time ensures that the temperature at the surface of the sample does not drop notably. More details of the instrument are given in Ref. [14].

\section{Results and discussion}

Figure 2 shows the compression stress-strain curves obtained for the $16 \mathrm{MnCr} 5$ steel at different strain rates and temperatures. At room temperature, a sharp yield point is observed in the tests carried out at $500 \mathrm{~s}^{-1}$ and

$2000 \mathrm{~s}^{-1}$. However, the sharp yield point disappears as the strain rate reaches $4500 \mathrm{~s}^{-1}$ and the yield behavior becomes more continuous. The strain hardening rate of the test material seems insensitive to the microstructure, and the obtained stress-strain curves are rather parallel. On the other hand, temperature seems to have a small effect on the shape of the curves. The steel strain hardens stronger at the highest test temperature, especially at 500 $\mathrm{s}^{-1}$ and $2000 \mathrm{~s}^{-1}$, but at $4500 \mathrm{~s}^{-1}$ the stress-strain curves at different temperatures are essentially parallel.
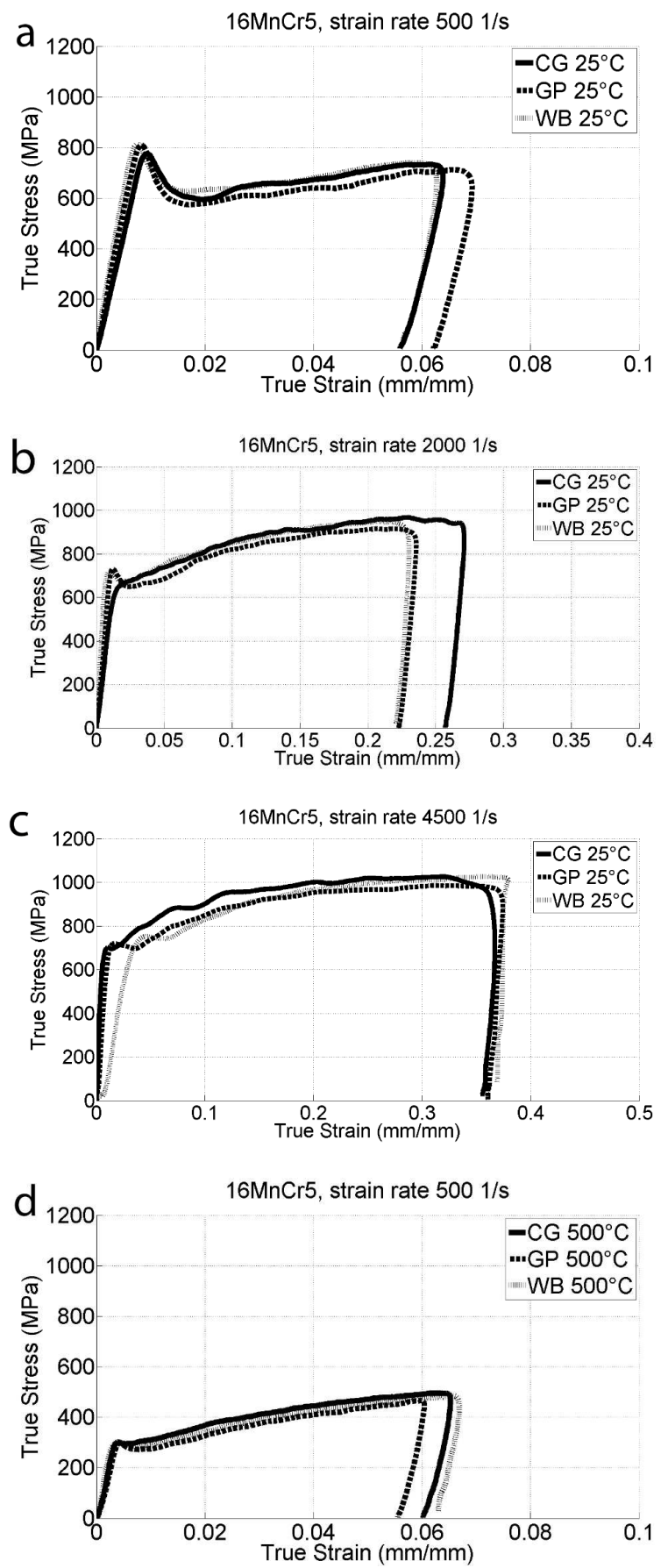

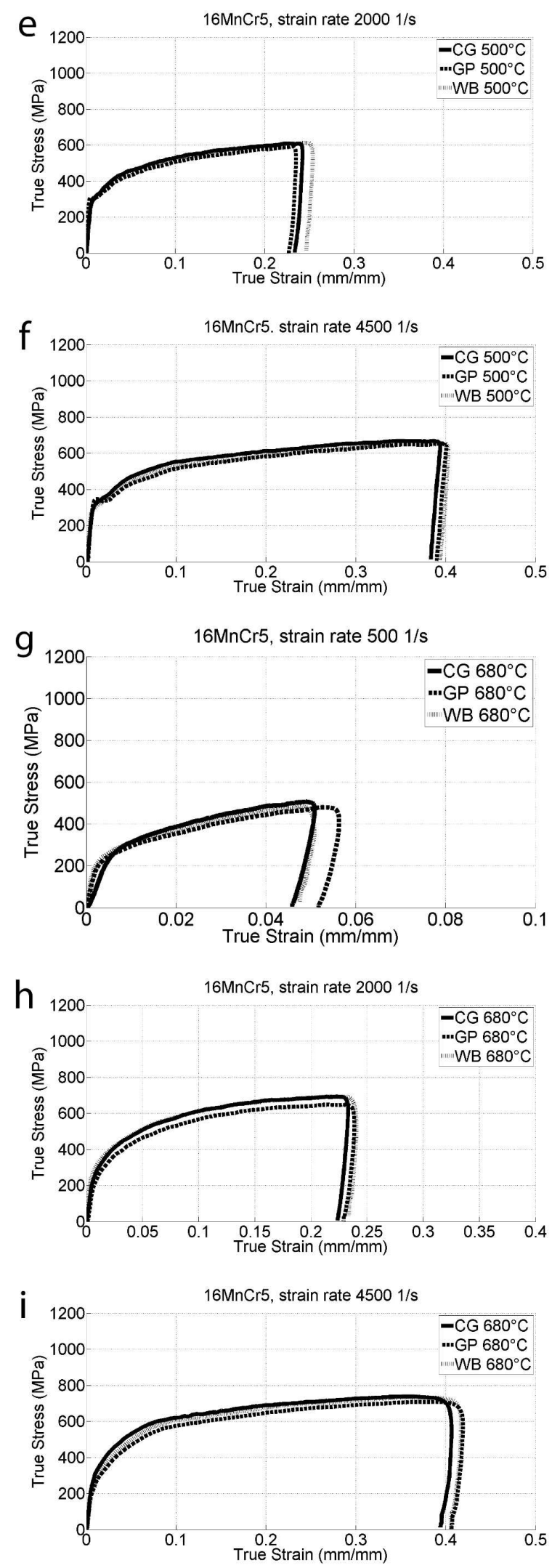

Fig. 2. Stress-strain curves at different temperatures for the $16 \mathrm{MnCr} 5$ steel at a) $25^{\circ} \mathrm{C}$ and $500 \mathrm{~s}^{-1}$, b) $25^{\circ} \mathrm{C}$ and $2000 \mathrm{~s}^{-1}$, c) $25{ }^{\circ} \mathrm{C}$ and $4500 \mathrm{~s}^{-1}$, d) $500{ }^{\circ} \mathrm{C}$ and $500 \mathrm{~s}^{-1}$, e) $500{ }^{\circ} \mathrm{C}$ and $2000 \mathrm{~s}^{-}$ ${ }^{1}$, f) $500{ }^{\circ} \mathrm{C}$ and $4500 \mathrm{~s}^{-1}$, g) $680{ }^{\circ} \mathrm{C}$ and $500 \mathrm{~s}^{-1}$, h) $680{ }^{\circ} \mathrm{C}$ and $2000 \mathrm{~s}^{-1}$, and i) $680{ }^{\circ} \mathrm{C}$ and $4500 \mathrm{~s}^{-1}$.
The deformation behavior is a bit different for the C60 steel, where a tendency for sharp yielding is observed for the CG and GP structures at room temperature at the strain rate of $500 \mathrm{~s}^{-1}$. However, the behavior changes again to continuous as the temperature and strain rate increase. When comparing the strength of the different variants of the C60 steel, it is evident that the microstructure has a much stronger influence on the flow stress than for the $16 \mathrm{MnCr} 5$ steel. The steel with the CG structure shows the highest strength at all strain rates, followed by the reference structure and the GP structure. Nonetheless, it seems that the strain hardening rate is less affected by the temperature, strain rate, and microstructure.

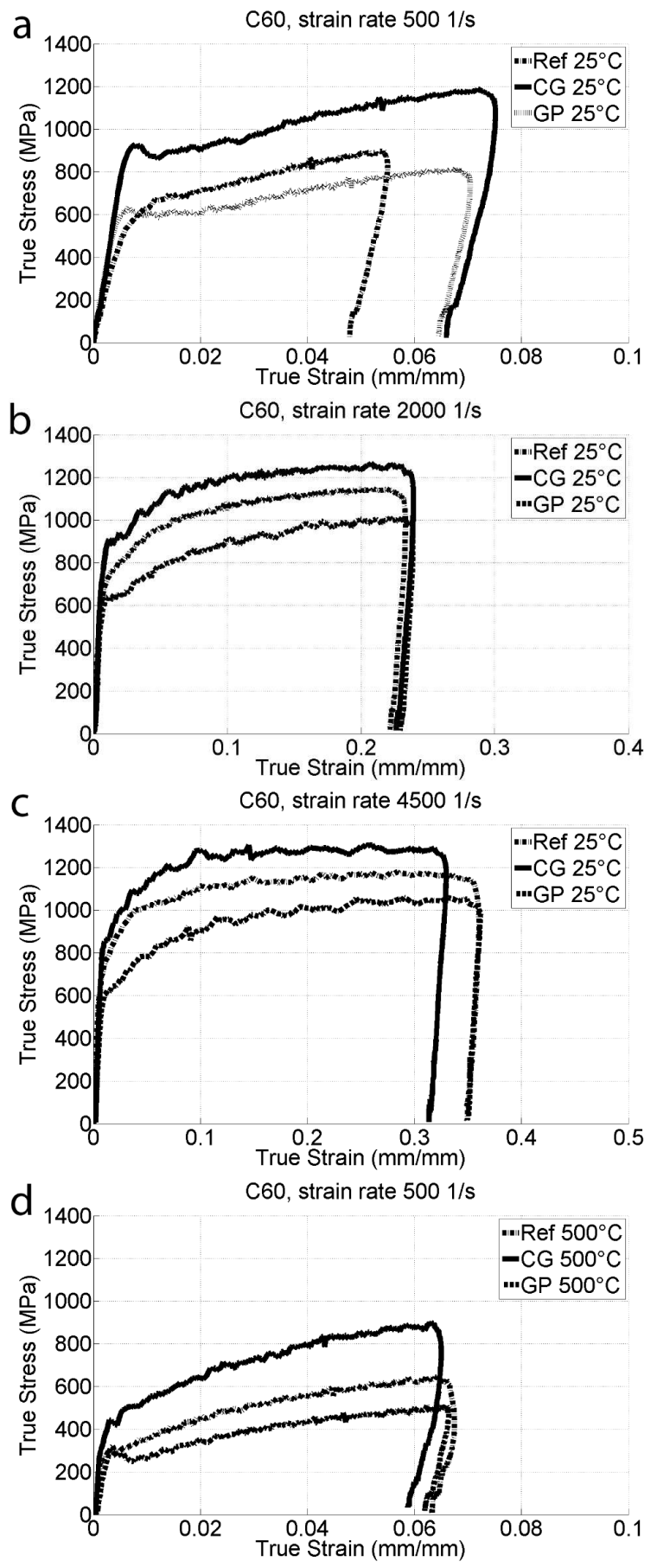



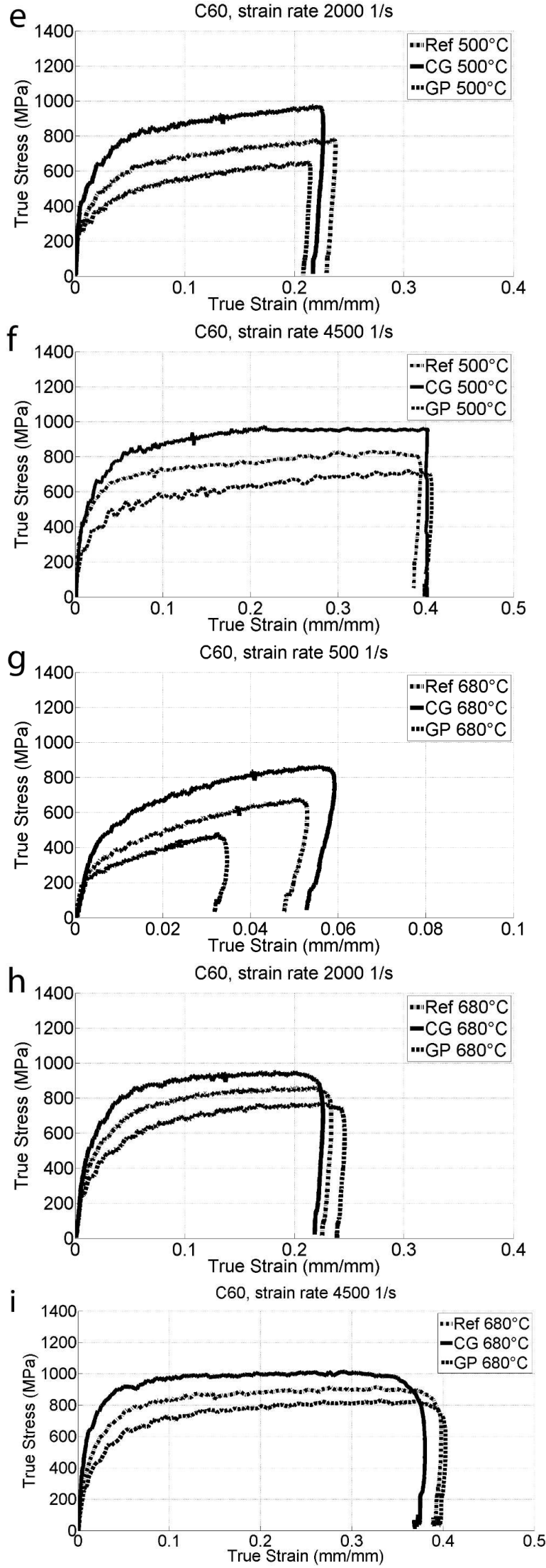

Fig. 3. Stress-strain curves at different temperatures for the C60 steel at a) $25{ }^{\circ} \mathrm{C}$ and $500 \mathrm{~s}^{-1}$, b) $25{ }^{\circ} \mathrm{C}$ and $2000 \mathrm{~s}^{-1}$, c) 25 ${ }^{\circ} \mathrm{C}$ and $4500 \mathrm{~s}^{-1}$, d) $500{ }^{\circ} \mathrm{C}$ and $500 \mathrm{~s}^{-1}$, e) $500{ }^{\circ} \mathrm{C}$ and $2000 \mathrm{~s}^{-1}$, f) $500{ }^{\circ} \mathrm{C}$ and $4500 \mathrm{~s}^{-1}$, g) $680{ }^{\circ} \mathrm{C}$ and $500 \mathrm{~s}^{-1}$, h) $680{ }^{\circ} \mathrm{C}$ and $2000 \mathrm{~s}^{-1}$, and i) $680{ }^{\circ} \mathrm{C}$ and $4500 \mathrm{~s}^{-1}$.
The effects of microstructure and temperature can be better seen by plotting the flow stress at $5 \%$ and $15 \%$ of plastic deformation as a function of temperature at a constant strain rate. Figure 4 shows the flow stress vs. temperature plots for both tested steels at the strain rate of $4500 \mathrm{~s}^{-1}$. A strong DSA effect is observed for all tested materials at this strain rate. The strength of all tested materials decreases considerably as the temperature increases from room temperature to $500{ }^{\circ} \mathrm{C}$. However, due to the DSA effect, the strength of the materials increases again as the temperature reaches 680 ${ }^{\circ} \mathrm{C}$.

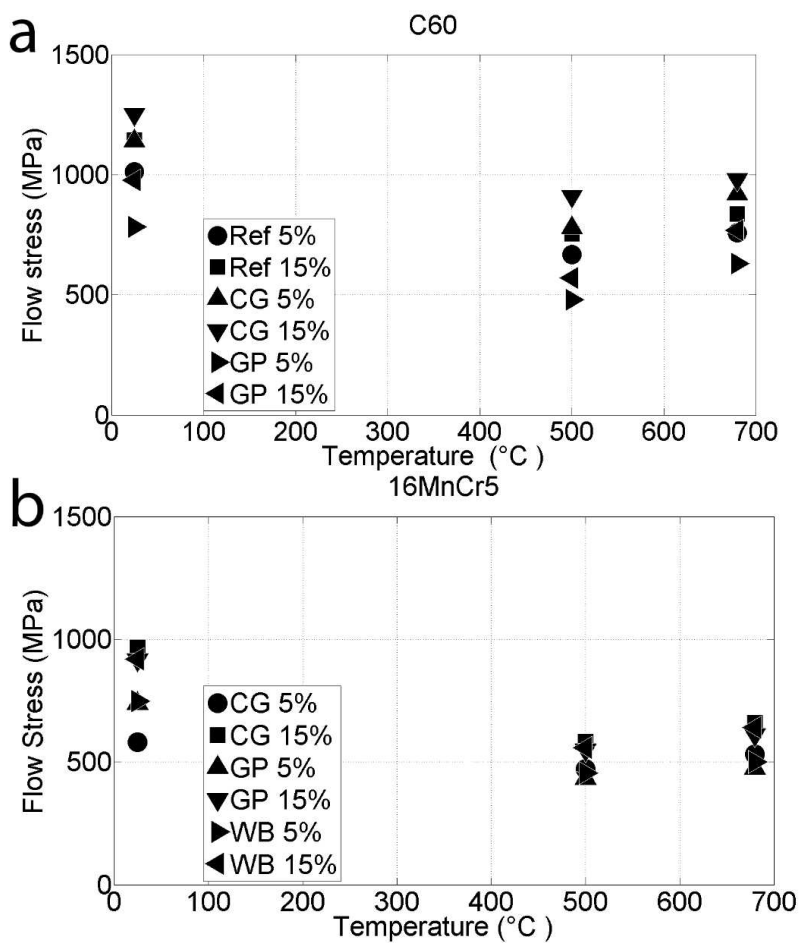

Fig. 4. Flow stress at $5 \%$ and $15 \%$ of plastic strain as a function of temperature at the strain rate of $4500 \mathrm{~s}^{-1}$ for a) C60 and b) $16 \mathrm{MnCr} 5$ steels.

The relative strength of the dynamic strain aging can be quantified using a temperature sensitivity factor, which is defined in Equation 1, where $\sigma_{\varepsilon \mathrm{RT}}$ and $\sigma_{\varepsilon \mathrm{T}}$ are the flow stresses at the constant plastic strain obtained at room temperature (RT) and at the higher temperature. The temperature sensitivity factor equals one at room temperature and has a value between zero and one at higher temperatures.

$$
\eta(\pi, \tau)=1-\frac{\sigma_{\varepsilon, A T}-\sigma_{\varepsilon T}}{\sigma_{z_{n}, A T}}
$$

Table 2 shows the temperature sensitivity factor as a function of temperature at the strain rate of $4500 \mathrm{~s}^{-1}$ for the $\mathrm{C} 60$ and $16 \mathrm{MnCr} 5$ steels. It is evident from the Figures that there is a strong increase in temperature sensitivity towards higher temperatures for both steels. The highest temperature sensitivity at 5\% plastic deformation is observed for the steels with a coarse grain structure. In general, the steels with a coarse grain structure show high temperature sensitivity for all studied temperatures. The globular pearlite structure has a rather low temperature sensitivity factor at $500{ }^{\circ} \mathrm{C}$ for 
both steels. However, the temperature sensitivity factor of the C60 globular pearlite increases more when the temperature is increased from $500{ }^{\circ} \mathrm{C}$ to $680{ }^{\circ} \mathrm{C}$ compared to the other microstructural variants. On the other hand, for the $16 \mathrm{MnCr} 5$ steel the globular pearlite structure shows the lowest $\eta$ values at $5 \%$ plastic deformation. At higher temperatures at $5 \%$ plastic strain, the coarse grain structure still shows the highest temperature sensitivity factor, followed by the globular structure and the banded structure. However, at $15 \%$ plastic strain the situation is somewhat different. All the three different structures for $16 \mathrm{MnCr} 5$ exhibit almost the same value for the temperature sensitivity factor at 500 ${ }^{\circ} \mathrm{C}$ and $680{ }^{\circ} \mathrm{C}$. It seems that as the deformation proceeds from $5 \%$ to $15 \%$, the sensitivity of the coarse-grained structure decreases and the sensitivity of the other microstructure variants increases, especially at the temperature of $680{ }^{\circ} \mathrm{C}$. At least for this particular steel, the microstructures seem to develop towards similar DSA conditions, and therefore at higher strains, the mobile dislocation density and the diffusional conditions appear to be (effectively) similar for all studied microstructural variants.

Table 2. Temperature sensitivity factor at different temperatures at the strain rate of $4500 \mathrm{~s}^{-1}$ for the C60 and $16 \mathrm{MnCr} 5$ steels.

\begin{tabular}{|c|c|c|c|c|c|c|}
\hline \multirow{2}{*}{$\mathrm{C} 60$} & \multicolumn{2}{|c|}{ Ref } & \multicolumn{2}{c|}{$\mathrm{CG}$} & \multicolumn{2}{c|}{$\mathrm{GP}$} \\
\cline { 2 - 7 } & $\begin{array}{c}500 \\
{ }^{\circ} \mathrm{C}\end{array}$ & $\begin{array}{c}680 \\
{ }^{\circ} \mathrm{C}\end{array}$ & $\begin{array}{c}500 \\
{ }^{\circ} \mathrm{C}\end{array}$ & $\begin{array}{c}680 \\
{ }^{\circ} \mathrm{C}\end{array}$ & $\begin{array}{c}500 \\
{ }^{\circ} \mathrm{C}\end{array}$ & $\begin{array}{c}680 \\
{ }^{\circ} \mathrm{C}\end{array}$ \\
\hline $5 \%$ & 0.66 & 0.75 & 0.68 & 0.81 & 0.61 & 0.80 \\
\hline $15 \%$ & 0.66 & 0.73 & 0.73 & 0.78 & 0.58 & 079 \\
\hline
\end{tabular}

\begin{tabular}{|c|c|c|c|c|c|c|}
\hline \multirow{2}{*}{$16 \mathrm{MnCr} 5$} & \multicolumn{2}{|c|}{$\mathrm{WB}$} & \multicolumn{2}{c|}{$\mathrm{CG}$} & \multicolumn{2}{c|}{$\mathrm{GP}$} \\
\cline { 2 - 7 } & $\begin{array}{c}500 \\
{ }^{\circ} \mathrm{C}\end{array}$ & $\begin{array}{c}680 \\
{ }^{\circ} \mathrm{C}\end{array}$ & $\begin{array}{c}500 \\
{ }^{\circ} \mathrm{C}\end{array}$ & $\begin{array}{c}680 \\
{ }^{\circ} \mathrm{C}\end{array}$ & $\begin{array}{c}500 \\
{ }^{\circ} \mathrm{C}\end{array}$ & $\begin{array}{c}680 \\
{ }^{\circ} \mathrm{C}\end{array}$ \\
\hline $5 \%$ & 0.61 & 0.67 & 0.81 & 0.92 & 0.59 & 0.64 \\
\hline $15 \%$ & 0.61 & 0.70 & 0.60 & 0.68 & 0.60 & 0.68 \\
\hline
\end{tabular}

\section{Concluding remarks}

- The ferritic-perlitic steels $16 \mathrm{MnCr} 5$ and $\mathrm{C} 60$ with different microstructures were tested at different dynamic strain rates at temperatures $25{ }^{\circ} \mathrm{C}, 500{ }^{\circ} \mathrm{C}$, and $680{ }^{\circ} \mathrm{C}$ to study the effects of microstructure and temperature on the temperature sensitivity of the materials.

- The mechanical response of the studied steels differs somewhat from one to another. All the steels exhibit a sharp yield point at the lower strain rates. However, when increasing the strain rate to $4500 \mathrm{~s}^{-1}$, the yield behavior becomes more continuous.

- $\quad$ For the $16 \mathrm{MnCr} 5$ steel, the microstructure does not have a significant impact on the strength after the yield point except for the globular pearlite structure, which exhibits a slightly lower strength, especially at lower strain rates. In general, the structure of the C60 steel has a stronger effect on the flow stress.

- $\quad$ At high strain rates, a strong dynamic strain aging effect is observed for all tested materials. In addition, as the temperature increases, the strength of the materials decreases significantly up to $500{ }^{\circ} \mathrm{C}$ at all strain rates. Due to the dynamic strain aging effect, the strength increases again as the temperature is increased to $680{ }^{\circ} \mathrm{C}$.

- $\quad$ For both the $\mathrm{C} 60$ and $16 \mathrm{MnCr} 6$ steels, the coarsegrained microstructure has the strongest temperature sensitivity at low plastic strains. At higher plastic strains, however, all studied microstructures exhibit similar strain aging sensitivities.

The funding by the European Research Fund for Coal and Steel in frame of the research project RFSR-CT-2014- 00020 (IMMAC) is gratefully acknowledged.

\section{References}

1. A. Portevin and F. Le Chatelier, "Trans. Am. Soc. Steel Treat, vol. 52, pp. 457-478 (1924)

2. S. Nemat-Nasser, W. Guo and J. Cheng, Acta Mater., vol. 47, no. 13, pp. 3705-3720 (1999)

3. S. Nemat-Nasser, Mater. Sci. Eng. A., vol. 284, no. 1-2, pp. 202-210 (2000)

4. S. Nemat-Nasser and W. Guo Mech. Mater, vol. 32, no. 4, pp. 243-260 (2000)

5. J. Cheng, S. Nemat-Nasser and W. guo, Mech. Mater., vol. 33, no. 11, pp. 603-616 (2001)

6. S. Nemat-Nasser, W. Guo and D. Kihl J. Mech. Phys. Sol., vol. 49, no. 8, pp. 1823-1846 (2001)

7. J. D. Baird and A. Jamieson, J. Iron. Steel. Inst. (1966)

8. A. Gilat and X. Wu, Int. J. Plasticity, vol. 13, no. 67, pp. 611-632 (1997)

9. M. Shahriary, B. Koohbor, K. Ahadi, A. ekrami, M. Khakian-Qomi and T. Izadyar, Mater. Sci. Eng. A, vol. 550, pp. 325-332 (2012)

10. D. Forni, B. Chiaia and E. Cadoni, Mater. Desi, vol. 94, , pp. 467-478 (2016)

11. J. D. Baird, Metall. Rev., vol. 149, no. 1, pp. 1-18 (1971)

12. J. Chakravartty, S. S. T. Wadekar, M. Asundi J. Nuc. Mater., vol. 119, no. 3, pp. 51-58 (1983)

13. D. Wagner, J. moreno and C. Prioul, J. Nuc. Materi., vol. 252, no. 3, pp. 257-265 (1998)

14. M. Hokka, Effects of strain rate and temperature on the mechanical behavior of advanced high strength steels, Tampere: Tampere University of Technology (2008) 